\title{
ResoluÇão de Problemas e as operações de adição E SUBTRAÇÃO NA FORMAÇÃO CONTINUADA DE PROFESSORES DOS ANOS INICIAIS DO ENSINO FUNDAMENTAL
}

\author{
SOLVING OF PROBLEM AND ADDITION AND SUBTRACTION OPERATIONS IN \\ THE CONTINUING EDUCATION OF TEACHERS FROM THE EARLY YEARS OF \\ ELEMENTARY SCHOOL
}

DOI: http://dx.doi.org/10.23926/RPD.2526-2149.2019.v4.n1.p5-23.id308

\author{
José Carlos Pinto \\ Leivas \\ Doutor em Educação \\ (Matemática) pela UFPR. \\ Professor do Programa de \\ Pós-Graduação em Ciências \\ e Matemática da \\ Universidade Franciscana- \\ UFN. \\ leivasjc@ufn.edu.br
}

\begin{abstract}
Resumo: Neste artigo, apresentamos resultados de uma pesquisa de cunho qualitativo, a qual teve por objetivo verificar como estudantes em ação continuada empregavam a estratégia da Resolução de Problemas para articular conteúdos envolvendo fatos da adição e subtração de números naturais. Para tal, foram propostos dois problemas, os quais apresentavam questionamentos que propiciavam aplicar as etapas dessa metodologia, na visão de autores consagrados da área, juntamente com a utilização de alguns recursos da teoria dos Registros de Representação Semiótica, a fim de fortalecer a alfabetização em Matemática relativa às duas operações, bem como fatos básicos envolvidos nas mesmas. Os resultados sugerem que a metodologia foi eficaz e que os participantes puderam refletir, tomar decisões e embasar sua prática profissional voltada aos Anos Iniciais do Ensino Fundamental.
\end{abstract}

Palavras-chave: Resolução de Problemas; BNCC; Anos Iniciais; Registros de Representação Semiótica.

\begin{abstract}
In this article, we present the results of a qualitative research, whose objective was to verify how students in continuous action used the problem solving strategy to articulate contents involving facts of addition and subtraction of natural numbers. To this end two problems were proposed, which presented questions that allowed to apply the steps of this methodology, in the view of consecrated authors of the area, together with the use of some resources of the theory of the Registers of Semiotic Representation, in order to strengthen literacy in Mathematics related to the two operations, as well as basic facts involved in them. The results showed that the methodology was effective and that the participants were able to reflect, make decisions and base the professional practice focused on the Early Years of Primary Education.

Keywords: Solving of Problems; BNCC; Initial Years; Registers of Semiotic Representation..
\end{abstract}




\section{INTRODUÇÃO}

A construção do número, o sistema de numeração decimal e as propriedades operatórias com números naturais, em nosso entender, são temas fundamentais para um bom desempenho do estudante no início da escolaridade. Desse modo, o papel do professor que atua nesse nível é mais relevante ainda, uma vez que, se este não conhece com certa profundidade o conteúdo e as metodologias que podem ser utilizadas, dificilmente irá propiciar aos alunos um desenvolvimento cognitivo e afetivo de qualidade. Algumas vezes, isso não ocorre nos cursos de formação inicial dos professores que atuam nos Anos Iniciais do Ensino Fundamental, e, nesse sentido, a busca por ações continuadas torna-se uma alternativa pertinente e profícua.

Segundo Freitas (2017), a própria Lei de Diretrizes e Bases da Educação Nacional recomenda que o ensino leve em consideração princípios como a liberdade de aprender, de ensinar, de pesquisar e de divulgar a cultura, o pensamento, a arte e o saber, dentre outros. $\mathrm{O}$ Referencial Curricular para a Educação Infantil também vem ao encontro dessa orientação, indicando que as crianças, desde o nascimento, estão inseridas no universo do qual faz parte o conhecimento matemático: números, relações entre quantidades e noções de espaço. (BRASIL, 1998).

Por sua vez, os Parâmetros Curriculares Nacionais, (BRASIL, 1997) recomendam que, nas séries iniciais (Anos Iniciais) do Ensino Fundamental, a criança deve saber: utilizar diferentes fontes de informação e recursos tecnológicos para adquirir conhecimentos; questionar a realidade formulando problemas; resolver problemas com criatividade, intuição e análise, selecionando procedimentos e verificando adequações para estes.

Ao chegarmos a Base Nacional Curricular Comum - BNCC, no que diz respeito à Educação Infantil e aos Anos Iniciais, buscamos elementos a respeito de números que justificassem o desenvolvimento de atividades junto a um grupo de professores e futuros professores que cursam a disciplina em um Programa de Pós-Graduação em Ensino de Ciências e Matemática. Tal disciplina é ofertada, especialmente, a professores com formação em Pedagogia que cursam o Mestrado Profissional, tendo por objetivo principal: analisar o papel da Matemática na formação dos professores dos Anos Iniciais; ter a Educação Matemática como campo do conhecimento capaz de selecionar e articular conteúdo desse nível de escolaridade com estratégias de ensino; organizar o trabalho pedagógico por meio de recursos didáticos pertinentes.

Assim, atendendo ao objetivo principal da disciplina, em uma aula desenvolvida durante uma manhã no mês de setembro de 2018, propusemos a utilização da metodologia de Resolução 
de Problemas para investigar o que segue: Como empregar a estratégia da Resolução de Problemas para articular conteúdos envolvendo fatos da adição e subtração de números naturais? Na busca de responder a tal problema de pesquisa, definimos o seguinte objetivo: verificar como estudantes em ação continuada empregavam a estratégia da Resolução de Problema para articular conteúdos envolvendo fatos da adição e subtração de números naturais. Na sequência, traremos fundamentos teóricos envolvendo o tema.

\section{FUNDAMENTAÇÃO TEÓRICA}

A partir das considerações anteriores, buscamos, na BNCC, orientações a respeito do tema número. Localizamos e escolhemos, nos quatro primeiros anos, na unidade temática números, o objeto do conhecimento e as habilidades, o que se encontra sistematizado no Quadro 1.

Quadro 1 - Conhecimentos e habilidades em números e operações

\begin{tabular}{|c|c|c|}
\hline Ano & Objeto do conhecimento & Habilidades \\
\hline $1^{\circ}$ & $\begin{array}{l}\text { Leitura, escrita, comparação e } \\
\text { ordenação de números de até três } \\
\text { ordens pela compreensão de } \\
\text { características do sistema de } \\
\text { numeração decimal (valor } \\
\text { posicional e papel do zero). }\end{array}$ & $\begin{array}{l}\text { (EF02MA01) Comparar e ordenar números naturais } \\
\text { (até a ordem de centenas) pela compreensão de } \\
\text { características do sistema de numeração decimal (valor } \\
\text { posicional e função do zero). }\end{array}$ \\
\hline $2^{\circ}$ & $\begin{array}{l}\text { Composição e decomposição de } \\
\text { números naturais (até 1000). }\end{array}$ & $\begin{array}{l}\text { (EF02MA04) Compor e decompor números naturais } \\
\text { de até três ordens, com suporte de material } \\
\text { manipulável, por meio de diferentes adições. }\end{array}$ \\
\hline $2^{\circ}$ & $\begin{array}{l}\text { Construção de fatos fundamentais } \\
\text { da adição e da subtração. }\end{array}$ & $\begin{array}{l}\text { (EF02MA05) Construir fatos básicos da adição e } \\
\text { subtração e utilizá-los no cálculo mental ou escrito. }\end{array}$ \\
\hline $2^{\circ}$ & $\begin{array}{l}\text { Problemas envolvendo diferentes } \\
\text { significados da adição e da } \\
\text { subtração (juntar, acrescentar, } \\
\text { separar, retirar). }\end{array}$ & $\begin{array}{l}\text { (EF02MA06) Resolver e elaborar problemas de adição } \\
\text { e de subtração, envolvendo números de até três ordens, } \\
\text { com os significados de juntar, acrescentar, separar, } \\
\text { retirar, utilizando estratégias pessoais ou } \\
\text { convencionais. }\end{array}$ \\
\hline $3^{\circ}$ & $\begin{array}{l}\text { Leitura, escrita, comparação e } \\
\text { ordenação de números naturais de } \\
\text { quatro ordens. }\end{array}$ & $\begin{array}{l}\text { (EF03MA01) Ler, escrever e comparar números } \\
\text { naturais até a ordem de unidade de milhar, } \\
\text { estabelecendo relações entre os registros numéricos e } \\
\text { em língua materna. }\end{array}$ \\
\hline $3^{\circ}$ & $\begin{array}{l}\text { Problemas envolvendo } \\
\text { significados da adição e da } \\
\text { subtração: juntar, acrescentar, } \\
\text { separar, retirar, comparar e } \\
\text { completar quantidades. }\end{array}$ & $\begin{array}{l}\text { (EF03MA06) Resolver e elaborar problemas de adição } \\
\text { e subtração com os significados de juntar, acrescentar, } \\
\text { separar, retirar, comparar e completar quantidades, } \\
\text { utilizando diferentes estratégias de cálculo exato ou } \\
\text { aproximado, incluindo cálculo mental. }\end{array}$ \\
\hline $4^{\circ}$ & $\begin{array}{l}\text { Problemas envolvendo } \\
\text { significados da adição e da } \\
\text { subtração: juntar, acrescentar, } \\
\text { separar, retirar, comparar e } \\
\text { completar quantidades. }\end{array}$ & $\begin{array}{l}\text { (EF03MA06) Resolver e elaborar problemas de adição } \\
\text { e subtração com os significados de juntar, acrescentar, } \\
\text { separar, retirar, comparar e completar quantidades, } \\
\text { utilizando diferentes estratégias de cálculo exato ou } \\
\text { aproximado, incluindo cálculo mental. }\end{array}$ \\
\hline
\end{tabular}




\begin{tabular}{|l|l|l|}
\hline $4^{\circ}$ & $\begin{array}{l}\text { Propriedades das operações para o } \\
\text { desenvolvimento de diferentes } \\
\text { estratégias de cálculo com } \\
\text { números naturais. }\end{array}$ & $\begin{array}{l}\text { (EF04MA03) Resolver e elaborar problemas com } \\
\text { números naturais envolvendo adição e subtração, } \\
\text { utilizando estratégias diversas, como cálculo, cálculo } \\
\text { mental e algoritmos, além de fazer estimativas do } \\
\text { resultado. }\end{array}$ \\
\hline
\end{tabular}

Fonte: adaptado da BNCC.

Como pode ser percebido no Quadro 1, a escrita, a composição e decomposição, os fatos fundamentais e os diferentes significados da adição e da subtração podem conduzir à formação inicial de conceitos capitais para o desenvolvimento matemático e a formação nessa área. Além disso, observamos a estratégia de empregar problemas para adquirir as habilidades a respeito. Essas considerações, por si só, justificam o problema enunciado na introdução do artigo e o objetivo da pesquisa em apreço.

Bittar e Freitas (2005) indicam que as crianças, ao ingressarem na escola, já possuem conhecimentos básicos das operações de adição e de subtração com números naturais, mesmo sem a concepção do zero. Assim, os autores recomendam a necessidade de "[...] partir do conhecimento da criança e não do zero, como se essa não tivesse conhecimento prévio e, além disso, a escola tem a tarefa de sistematizar esses conhecimentos, proporcionando a construção do pensamento matemático pela criança” (p. 56). Para os pesquisadores, por elas já possuírem algum conhecimento intuitivo dessas operações, não é necessário que sejam apresentadas inicialmente, de forma isolada.

No que diz respeito à origem dos conceitos de adição e subtração, Nunes et al. (2009) remetem às contribuições deixadas por Piaget sobre os esquemas de ação das crianças. Segundo os autores, os "esquemas de ação a partir dos quais a criança começa a compreender a adição e a subtração são representações das ações de juntar, retirar, respectivamente” (p. 46). Para os pesquisadores, em alguns problemas, a solução simples de adição e subtração usa esquemas de ação, pois as relações parte-todo podem ser aplicadas a qualquer objeto, como, por exemplo, os dedos, o papel, tracinhos, blocos, não importando o material empregado, e sim a ação realizada.

A respeito de contar nos dedos, Lopes e Leivas (2017) investigaram a relação entre a operação de adição e os procedimentos de crianças ao contar nos dedos. De acordo com os autores, a pesquisa "Teve como objetivo analisar a importância da adição de modo puramente aritmético ou por meio de situações problemas. A pesquisa envolveu desde a construção do número, que é um fundamento necessário para poder estudar como ela faz a adição, e a importância da contagem nos dedos como ferramenta concreta para a efetuação dos cálculos.” (p. 1). 
Para Nunes et al. (2009), em alguns problemas, a solução simples de adição e subtração usa esquemas de ação, pois as relações parte-todo podem ser aplicadas a qualquer objeto, como, por exemplo, os dedos, o papel, tracinhos, blocos, não importando o material empregado, e sim a ação realizada. Indo um pouco mais além,

\begin{abstract}
a criança que já compreende a possibilidade de coordenar a resolução prática de problemas, obtida através de seus esquemas de ação, e o sistema de numeração já está começando a "aprender matemática", isto é, a usar os instrumentos e símbolos da matemática para a resolução de problemas. (NUNES et al., 2009, p. 48).
\end{abstract}

Portanto, os autores salientam a necessidade de coordenar o sistema de numeração com a resolução de problemas, de modo a solucionar, de maneira mais simples, nas palavras deles , os problemas propostos pelo professor. Isso reforça a síntese indicada no Quadro 1, em termos das habilidades indicadas no tratamento do tema números. Além disso, ao apresentar o indicativo da Resolução de Problemas como metodologia, esta parece indicar maior possibilidade de alcançar e desenvolver tais habilidades, conforme destacaremos a seguir.

Inicialmente, trazemos, de forma resumida, algumas concepções a respeito dessa metodologia. Polya (2006) apresenta etapas nas quais explicita ser a função do professor auxiliar os seus alunos, o que é uma habilidade que se adquire por imitação e prática, como qualquer outra. $\mathrm{O}$ pesquisador propõe indagar qual é a incógnita envolvida no problema, o que é necessário no problema e o que queremos e devemos procurar neste. As quatro fases indicadas pelo autor são apresentadas a seguir.

- Compreender o problema: ao procurar a solução de um problema, podemos variar nosso ponto de vista, maneira de encará-lo, mudar de posição. É necessário compreender claramente o problema.

- Estabelecer um plano: devemos investigar os diversos itens que estão inter-relacionados e como a incógnita está ligada aos dados fornecidos.

- Executar o plano: colocar em ação os passos delineados no plano.

- Fazer retrospectiva da resolução: é importante retomar a solução obtida, analisando-a e discutindo-a.

Uma segunda tendência sobre a metodologia é a de Van de Walle (2009), que traz a concepção de acordo com os NCTM ao afirmar: "A maioria, senão todos, dos conceitos e procedimentos matemáticos podem ser ensinados melhor através da Resolução de Problemas." 
(p. 57). Ele indica o conceito, segundo Hiebert et al. $(1997)^{1}$, de que um problema é definido como qualquer tarefa ou atividade na qual os estudantes não tenham nenhum método ou regra já receitados ou memorizados, e nem haja uma percepção por parte dos estudantes de que exista um método ‘correto' específico de solução. Os autores também indicam alguns pontos a serem levados em consideração, vistos a seguir.

- O problema deve começar onde os alunos estão. Isso significa que o projeto a ser proposto deve levar em consideração o estágio em que o estudante se encontra.

- O aspecto problemático ou envolvente do problema deve estar relacionado à Matemática que os alunos vão aprender, quer dizer, os alunos devem estar preocupados, principalmente, em dar significado à Matemática envolvida e, assim, desenvolver sua compreensão sobre essas ideias.

- A aprendizagem matemática dever requerer justificativas e explicações para as respostas e os métodos. A justificativa é parte integrante de suas soluções.

Van de Walle (2009) recomenda as seguintes estratégias e processos, apresentados a seguir.

- Desenvolver habilidades de análise de problemas: analisar um problema pouco conhecido, identificar informações desejadas e necessárias, ignorar as informações dispensáveis e expressar claramente o objetivo a alcançar.

- Desenvolver e selecionar estratégias: selecionar e usar estratégias adequadas para a resolução.

- Justificar as soluções: desenvolver habilidade de justificativa.

- Estender ou generalizar problemas: para ensinar os alunos a irem além da solução do problema específico.

Uma terceira forma de compreender a Resolução de Problemas é a de Dante (2003), que começa suas incursões com alguns questionamentos e respectivas respostas: o que é um problema? O que é um problema matemático? Ele apresenta, em seguida, os objetivos da metodologia: fazer o aluno pensar produtivamente; desenvolver o raciocínio lógico do estudante; ensiná-lo a enfrentar situações novas; dar-lhe a oportunidade de se envolver com as aplicações da Matemática; tornar as aulas de Matemática mais interessantes e desafiadoras;

\footnotetext{
${ }^{1}$ Citado por WALLE, John Van de. Matemática no ensino fundamental: formação de professores e aplicação em sala de aula. 6. ed. Porto Alegre: Artes Médicas, 2009, p. 57
} 
equipar o aluno com estratégias para resolver problemas e dar uma boa base matemática às pessoas.

Neste apanhado a respeito da Resolução de Problemas, trazemos a concepção de Onuchic e Alevatto (2011), as quais indicam terem assumido tal concepção ao trabalhar a Matemática através da resolução de problemas em seu grupo de estudos, em que empregam a palavra composta ensino-aprendizagem-avaliação, ampliando o leque dos autores precedentes, na medida em que exploram a dinâmica de trabalho na sala de aula. Para as pesquisadoras, os três elementos ocorrem simultaneamente, pois "enquanto o professor ensina, o aluno, como participante ativo, aprende, e que a avaliação se realize por ambos. $\mathrm{O}$ aluno analisa os próprios métodos e soluções obtidas para os problemas, visando sempre à construção de conhecimento" (p. 81). As autoras entendem que esse tipo de trabalho conduz o estudante ao próprio pensar matematicamente, elaborando justificativas de dar significado à solução do seu problema, enquanto ao professor cabe avaliar o que está ocorrendo na sala de aula. Assim, na metodologia, o ponto de partida corresponde sempre a um problema.

Conforme indicado no Quadro 1, é esperado das crianças, em termos de alfabetização matemática numérica, a leitura, a escrita e a comparação de números de até quatro ordens. Para isso, a BNCC sugere o desenvolvimento da habilidade de estabelecer relações entre os registros numéricos e em língua materna (EF03MA01). Assim, julgamos pertinente empregar alguns aspectos da Teoria dos Registros de Representação Semiótica (DUVAL, 2009) para o desenvolvimento de tais habilidades. Para o autor, essas representações são caracterizadas por estarem relacionadas a particulares sistemas de signos, como "a linguagem, a escrita algébrica ou os gráficos cartesianos, e em poderem ser convertidas em representações 'equivalentes' em outro sistema semiótico, mas podendo tomar significações diferentes para os sujeitos que as utilizam" (p. 32).

Não pretendemos aprofundar essa teoria neste artigo, mas utilizar os registros figurais ou simbólicos e os em língua materna no início da escolaridade dos Anos Iniciais, onde julgamos importante explorar, conjuntamente com a resolução de problemas, os tipos de registros que as crianças possam empregar. Em outras palavras, não há necessidade, nessa teoria, de exigirmos um único tipo de registro, o que pode despertar o interesse delas pela Matemática e os registros das diversas estratégias de resolução, como recomenda a BNCC.

$\mathrm{Na}$ sequência do artigo, apresentamos os procedimentos metodológicos, a coleta e análise dos dados. 


\section{Procedimentos metodológicos da PeSQuisa}

Realizamos esta pesquisa junto a um grupo em formação continuada, constituído de 11 participantes, os quais foram identificados com letras maiúsculas do alfabeto, a fim de preservar suas identidades. A pesquisa ocorreu em uma aula da disciplina 'Matemática para os Anos Iniciais: fundamentos e estratégias'. Trata-se de uma pesquisa qualitativa no ensino, como indicado por Moreira (2011), para quem:

a retórica qualitativa não evita a linguagem cotidiana carregada de valores; é detalhada, provendo elementos em quantidade suficiente - citações, vinhetas, documentos, comentários interpretativos - para persuadir o leitor de que as asserções de conhecimento são interpretações válidas daquilo que os eventos significam do ponto de vista dos sujeitos da pesquisa. (p. 58)

Reiterando o aspecto qualitativo de nossa pesquisa, no que diz respeito aos significados dos textos dos indivíduos envolvidos com esta, Guimarães (2009) afirma: “[...] Assim, analisar e interpretar envolve compreender a forma como os dados foram organizados e apresentados, para podermos fazer interpretações, inferências e predições”. (p.137). Ao realizar tal tipo de investigação com estudantes em ação continuada, fornece ao professor ações e atitudes futuras que venham a incrementar/aperfeiçoar sua prática profissional, de modo a formar indivíduos com possibilidades de atuar/orientar profissionais daquele segmento no qual o conteúdo é desencadeado.

Muito embora a disciplina seja ofertada, preferencialmente, ao Mestrado Profissional, também podem participar estudantes do Mestrado Acadêmico e do Doutorado, o que, de fato, ocorreu, uma vez que estes últimos alegam desconhecer esse tipo de disciplina na formação inicial do professor de Matemática. A fim de não discriminar a formação de cada um deles, e não propiciar pré-julgamentos, esta pesquisa não fez associação entre a identificação do indivíduo e sua formação.

O aluno recebeu um clip com uma síntese das concepções dos autores sobre a metodologia de Resolução de Problemas. Em seguida, a proposta de um problema para aplicar as etapas definidas pelos autores na resolução. Na sequência, foi recolhido o registro de cada um para a análise e repetido o processo para outra atividade. Assim, a coleta de dados foi obtida por meio dos registros escritos dos alunos, individualmente, e repassadas para posterior análise. A identificação desse registro foi feita pela letra designada para cada um.

No que diz respeito ao delineamento do corpus, em uma pesquisa qualitativa, podem ser úteis, segundo Bauer e Gaskell (2015), os seguintes aspectos: relevância, homogeneidade e sincronicidade. Para eles, "os assuntos devem ser relevantes e coletados a partir de um ponto 
de vista apenas" (p. 55). No caso da presente pesquisa, a relevância está em analisar como ocorre a resolução de um problema abordando números, com vista a um posicionamento didático do professor para atuar nos Anos Iniciais do Ensino Fundamental.

Quanto aos materiais coletados, devem ser homogêneos, tanto quanto possível, segundo os autores. Nesse sentido, as produções textuais dos indivíduos, feitas individualmente sobre o mesmo tema, na resolução de um mesmo problema, podem e devem servir ao pesquisador para a análise individual, dando um caráter qualitativo à avaliação da compreensão da metodologia e possibilidades de replicação pelos professores em suas salas de aula. Por último, os autores indicam a sincronicidade, ou seja, a análise ou estudo do material deve seguir um processo natural de evolução (sincronia), de modo a verificar se ocorreu ou não a mudança comportamental. Isso vai ao encontro do indicado por Onuchic e Allevato a respeito de introduzir a avaliação na metodologia de Resolução de Problemas, para além do que os outros autores indicam.

No transcurso da aula, apresentamos atividades diversas em que os alunos explorariam os registros de representação semiótica na resolução de problemas. Propusemos, por escrito, dois deles para compor este artigo, com os respectivos encaminhamentos a serem fornecidos ao professor para análise, o que constará a seguir.

\section{Resultados}

O primeiro problema foi proposto por Van de Walle (2006, p. 66) e, segundo o autor, destina-se a crianças pequenas (antiga primeira série do Ensino Fundamental).

Maria tinha economizado $\mathrm{R} \$ 9,00$. No dia seguinte, ela recebeu dinheiro para o lanche na escola. Agora ela tem $\mathrm{R} \$ 12,00$. Quanto ela recebeu para o lanche?

Os alunos receberam a seguinte sequência para orientar a resolução:

1. Como você faria isso sem usar calculadora?

2. Você pode escrever um registro de representação semiótica simbólico para isso?

3. Como você descreveria tal registro simbólico em linguagem natural?

4. É um problema aditivo; subtrativo ou ambos?

Os alunos, além desses elementos fornecidos por escrito, receberam uma folha em branco, a qual identificariam com a letra do alfabeto designada e devolveriam ao professor. $\mathrm{O}$ Quadro 2 sintetiza as respostas dos indivíduos ao primeiro item. 
Quadro 2 - Síntese das respostas ao primeiro item

\begin{tabular}{|c|c|}
\hline Participante & Resposta \\
\hline A & Usaria pensamento lógico. \\
\hline B & Representaria a situação através de um desenho e depois discutindo com os alunos. \\
\hline $\mathrm{C}$ & $\begin{array}{l}\text { I I I I I I I I I } \\
\text { I I I I I I I I I I I I } \rightarrow \text { Recebeu } R \$ 3,00 .\end{array}$ \\
\hline $\mathrm{D}$ & $\begin{array}{l}\text { É possível ir completando com unidades até encontrar o valor desejado. E, então, } \\
\text { verificar quantas unidades foram acrescentadas ao total. }\end{array}$ \\
\hline $\mathrm{E}$ & Representar o problema com símbolos matemáticos $9+?=12$. \\
\hline $\mathrm{F}$ & Faria com representação simbólica: $9,00+$ \\
\hline $\mathrm{G}$ & Bem, pensaria que tenho 9,00, quanto a mais ganhei para chegar a 12,00. \\
\hline $\mathrm{H}$ & Criança-contaria nos dedinhos quanto falta de 9 para 12. \\
\hline I & Sim. \\
\hline $\mathrm{J}$ & $\begin{array}{l}\text { Eu- primeira série - contaria nos dedos }-9 \longrightarrow 10,11,12=3 \text {. } \\
\text { Eu-professora - mentalmente. }\end{array}$ \\
\hline K & $\begin{array}{l}\text { Pelo método da contagem, se eu tinha } 9 \text { contaria até } 12 \text { que ela ficou, e observaria } \\
\text { quanto aumentou. }\end{array}$ \\
\hline
\end{tabular}

Fonte: elaborado pelo autor.

Observamos, nas respostas dos indivíduos, dificuldades de se colocarem na posição da criança para responder de maneira mais simples possível. Isso indica a importância de preparar o professor para atuar nos Anos Iniciais, de forma a compreender o aluno e não acelerar o processo, antecipando métodos e algoritmos. Percebemos, também, que esses professores participantes da atividade buscaram, de alguma forma, utilizar os registros de representação semiótica, assunto que foi abordado em aulas anteriores e que seria o objeto do segundo item. Em nosso entender, o professor de Matemática, particularmente, tende a dar respostas préelaboradas aos alunos, não aguardando que estes elaborem seu pensamento, o que é fundamental na primeira fase da metodologia de Resolução de Problemas, a saber, compreender o problema, sendo ele um auxiliar de seus alunos. É interessante, nessa metodologia, que busquemos qual é a incógnita, não com a denominação matemática, mas com a ideia de buscar algo, o que queremos no problema, o que devemos procurar e, com isso, desenvolver a habilidade prática na resolução de um problema (POLYA, 2006).

B, C, D, G, H e I se aproximaram mais do que era esperado para o nível proposto. Os tracinhos representados por C vão ao encontro do que foi indicado por Nunes et al. (2009) e correspondem mais ao item seguinte.

No que diz respeito ao segundo item, isto é, fazer um registro de representação semiótica para o problema, A, C, E e G exploraram representações matemáticas já elaboradas, como 12$9,12-9=3$ ou $9+3=12$, ou seja, com a notação para subtração e adição. Inclusive, usaram $9+$ $\mathrm{x}=12,00$ e x=3,00, fato que só irá ocorrer pelo sexto ano do Ensino Fundamental. 
$\mathrm{O}$ participante $\mathrm{E}$, anteriormente, havia respondido que seria resolvido o problema com símbolos matemáticos, $9+?=12$, fazendo a seguinte representação figural (Figura 1):

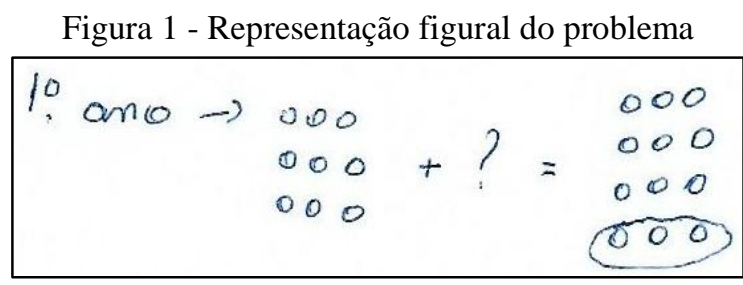

Fonte: estudante $\mathrm{E}$

Nessa representação figural, percebemos o indicado por Van de Walle (2009) sobre a metodologia, a saber, de que um problema é caracterizado como qualquer atividade que conduza o estudante a 'criar' o próprio método para resolvê-lo.

$\mathrm{Na}$ Figura 2, ilustramos a representação figural do problema, feita por B, coerentemente com o que havia sido registrado no item anterior.

Figura 2 - Representação figural feita por B

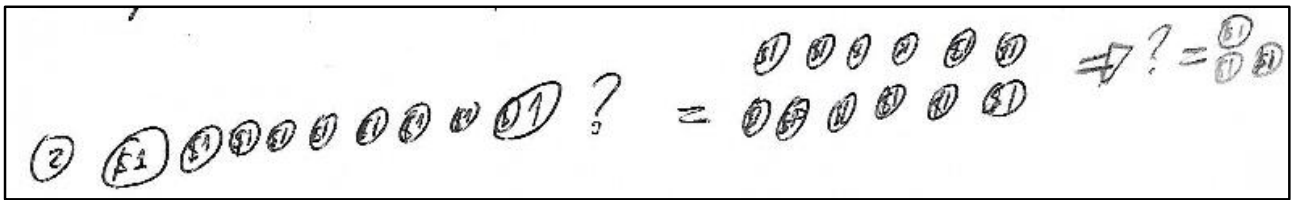

Fonte: arquivo do pesquisador.

Percebemos, na solução apresentada por B, o recomendado por Onuchic e Alevatto (2011), sobre a metodologia conduzir o indivíduo a pensar de forma própria, dando significado à solução que encontrou.

Outra forma de representação figural consta na Figura 3.

Figura 3 - Representação figural do item 2 do primeiro problema feita por $\mathrm{F}$

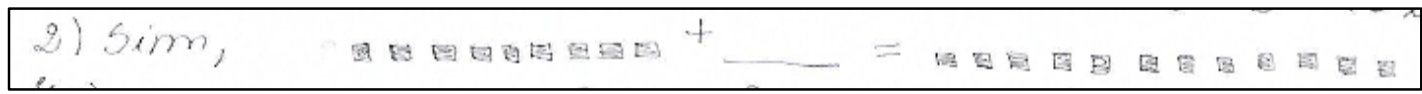

Fonte: arquivo da pesquisa.

No registro apresentado por $\mathrm{F}$, constatamos o que é indicado no Quadro 1, quanto à importância de o aluno estabelecer relações entre os registros na solução de um problema.

Interessante, ao nível de escolaridade pretendido com o problema 1, é a representação figural feita pelo participante I, constante da Figura 4, similarmente ao feito pelo indivíduo anterior, estabelecendo relações entre as representações figurais e o sistema de numeração para a resolução do problema. Essas soluções também vão ao encontro da escolha/definição de estratégias preconizadas pela metodologia de Resolução de Problemas. 
Figura 4 - Representação figural realizada por I

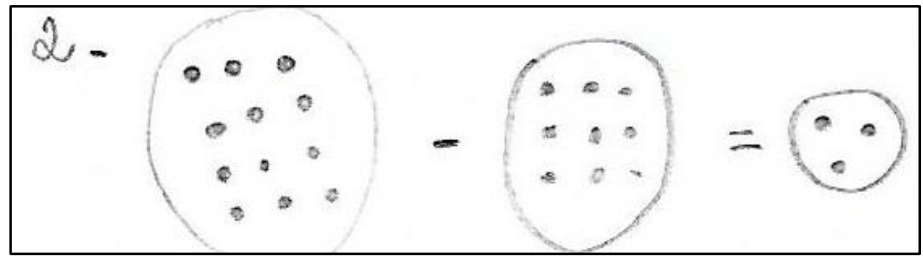

Fonte: arquivo do pesquisador.

Uma forma muito similar de registro figural é o que consta da Figura 5, diferenciandose pelos registros em língua natural, indicados ao lado, inclusive com destaque feito a um dos grupamentos de três, indicando o resto da subtração e reforçando o indicado em EF03MA01.

Figura 5 - Registro de representação figura feita por J

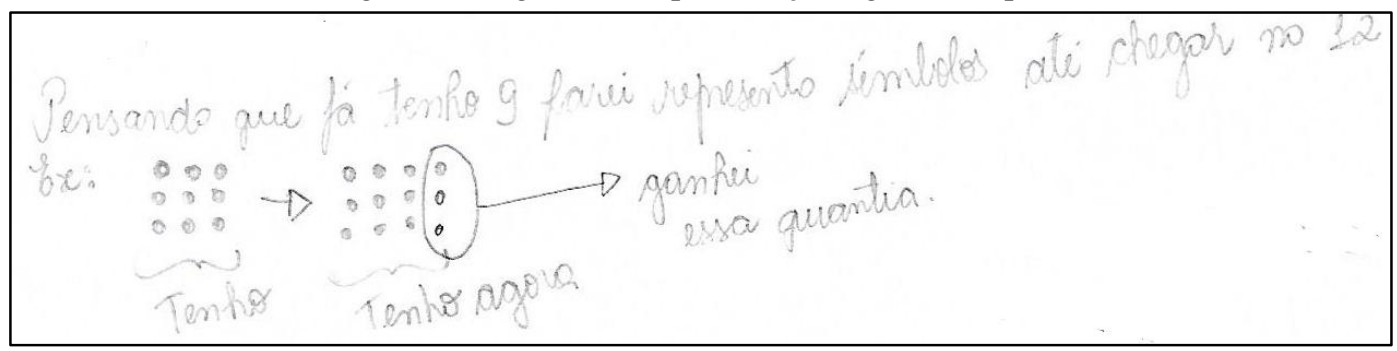

Fonte: arquivo do pesquisador.

$\mathrm{Na}$ sequência, os estudantes foram convidados a responder como descreveriam o registro simbólico, em linguagem natural, na estratégia definida para a resolução do problema.

C: Tenho 12 unidades e retiro 9 unidades. Restam 3 unidades.

D: Se tenho 9 reais, mais 1 real, obtenho 10 reais; mais 1 real, obtenho 11 reais e mais 1 real obtenho 12 reais. Assim, juntei ao todo 3 reais, a quantia que já possuía.

F: É agrupar de 3 em 3 para identificar a diferença ou agrupar até que a criança perceba a semelhança e a diferença. [coloca ao lado a representação figural correspondente à Figura 6].

Figura 6 - Registro natural associado ao figural

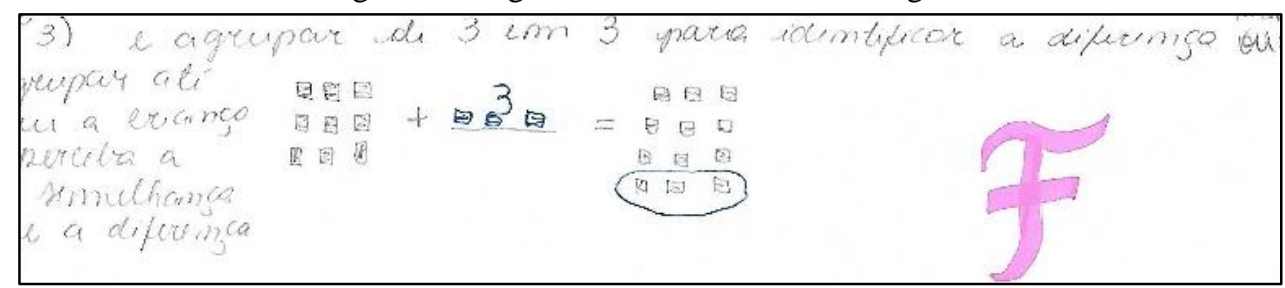

Fonte: registro de F.

I: Maria tinha $R \$ 12,00$ e antes tinha $R \$ 9,00$. Efetuando a subtração, vemos que ela ganhou $R \$ 3,00$ para o lanche.

$\mathrm{J}: 9,10,11,12=3$ reais que me deram. 
Percebemos que nenhum dos que buscaram usar a linguagem materna para expressar a solução pedida foram felizes, misturando o simbólico e o numeral com a linguagem, o que parece indicar uma dificuldade que tais indivíduos têm de expressar-se para além da linguagem da Matemática, ou seja, os símbolos. Essa, em nosso entender, é uma falha na formação do professor, em geral, de expressar a Matemática, quase que exclusivamente em sua linguagem própria, ou seja, a simbólica, talvez ocasionando a dificuldade na aprendizagem dessa disciplina.

K: Nove para doze faltam quantos? Esse indivíduo expressa a linguagem natural correspondente ao problema, com a ideia aditiva do faltar ou completar, e deixa como pergunta, não como afirmação.

No sentido de verificar se os participantes da investigação conseguiam, por meio da resolução de problemas e dos registros de representação semiótica, identificar se o problema era aditivo, subtrativo ou ambos, constatamos que todos responderam que eram ambos, entretanto alguns apresentaram argumentações ou justificativas, como as que seguem. Muito embora não tenha sido dado aprofundamento aos registros semióticos, nem tampouco rigor na exploração destes, podemos perceber que não chegou a ocorrer a conversão entre os registros (DUVAL, 2006), o que não era intencional na pesquisa. Porém, parece que isso auxiliou os indivíduos a identificarem que o problema poderia ser caracterizado como aditivo ou subtrativo, por terem explorado fatos básicos da adição e da subtração para resolvê-lo (EF02MA05), bem como os significados de juntar, acrescentar, separar e retirar, utilizando estratégias pessoais ou convencionais. (EF02MA06).

D: Na solução apresentada é aditivo. Mas pode, também, ser resolvido com recursos da subtração.

F: Ambos, pois poderia fazer operação de adição e subtração e pode fazer simbolicamente.

G: Acredito que ambos, porque posso acrescentar 3,00 + 9,00 ou diminuir 12,00-9,00.

I: Pode ser subtrativo, se a criança subtrair nove de 12.

$\mathrm{K}$ : Ambos, pois posso pensar em subtrair o total do que ela tinha ou posso adicionar do nove o 12 quantos aumentaram.

O segundo problema constante da pesquisa foi retirado de Van de Walle (p. 64), sendo recomendado para a segunda série (antiga) do Ensino Fundamental.

Papai disse que são 305 quilômetros até a praia. Quando paramos para abastecer o carro, já havíamos percorrido 267 quilômetros. Quantos quilômetros ainda temos de percorrer? 
Observamos, comparativamente ao primeiro problema, que o segundo envolveu valores numéricos naturais de até três ordens, com suporte de material manipulável, por meio de diferentes adições (EF02MA04). Além disso, conforme a BNCC, tal problema envolve adição e subtração com números de até três ordens, tendo os significados de juntar, separar e retirar, utilizando estratégias pessoais e convencionais (EF02MA06). Entendemos que a metodologia de Resolução de Problemas, bem como o auxílio de Registros de Representação Semiótica, constituiu estratégias adequadas, como indicado.

A fim de levar a cabo a pesquisa, encaminhamos (por escrito), a cada um dos participantes, as seguintes orientações que deveriam ser respondidas por escrito.

1. Como você faria isso para resolver sem calculadora? (Compreenda o problema)

2. Elabore um plano para resolução.

3. Discuta o plano com seu colega.

4. Reveja a solução. Sugestão: utilize registros de representação semiótica e QVL.

5. Quais os fatores operacionais relacionados no problema?

No que segue, passamos à análise dos dados coletados sobre o problema proposto. Muitos deles já realizaram a subtração de imediato, registrando $305-267=38$, o que nos parece, ainda, inapropriado para o nível a que se destina o problema. Aqui, induzimos que já seria conhecido o algoritmo ou o uso de calculadora, que não é o propósito do primeiro item.

No que diz respeito à compreensão do problema, outros estudantes indicaram a ideia do 'quanto falta', o que faz sentido para o caso, bem como o uso de cálculo mental. Assim registrou F:

Figura 7 - Dados fornecidos por F

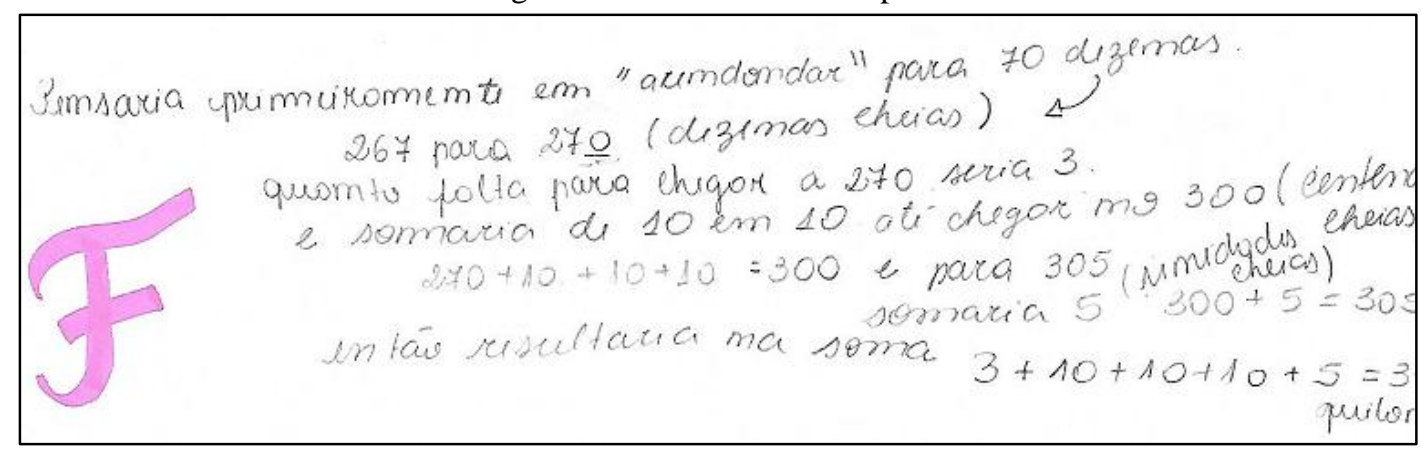

Fonte: dados da pesquisa

Ao que tudo indica, a concepção do estudante a respeito do nível de escolaridade e a forma como um aluno desse nível resolveria o problema é coerente, inclusive, como o indicado pela BNCC a respeito de estratégias para dar os significados de juntar, separar e retirar. Nesse 
sentido, completar unidades para chegar a dezenas cheias, posteriormente, completando as centenas cheias, parece ser uma boa estratégia e compatível com o $2^{\circ}$ ou $3^{\circ}$ ano do Ensino Fundamental. O estudante faz, ainda, uma síntese, ao retomar a discussão com os colegas, como segue.

$267=2$ centenas +6 dezenas +7 unidades;

$267+3$ unid. $=270$ (dezenas cheias);

$270+30$ dez. $=300$ (centenas cheias);

$300+5$ unid. $=305$ (unidades cheias).

Figura 8 - Solução do problema 2 apresentado por $\mathrm{F}$

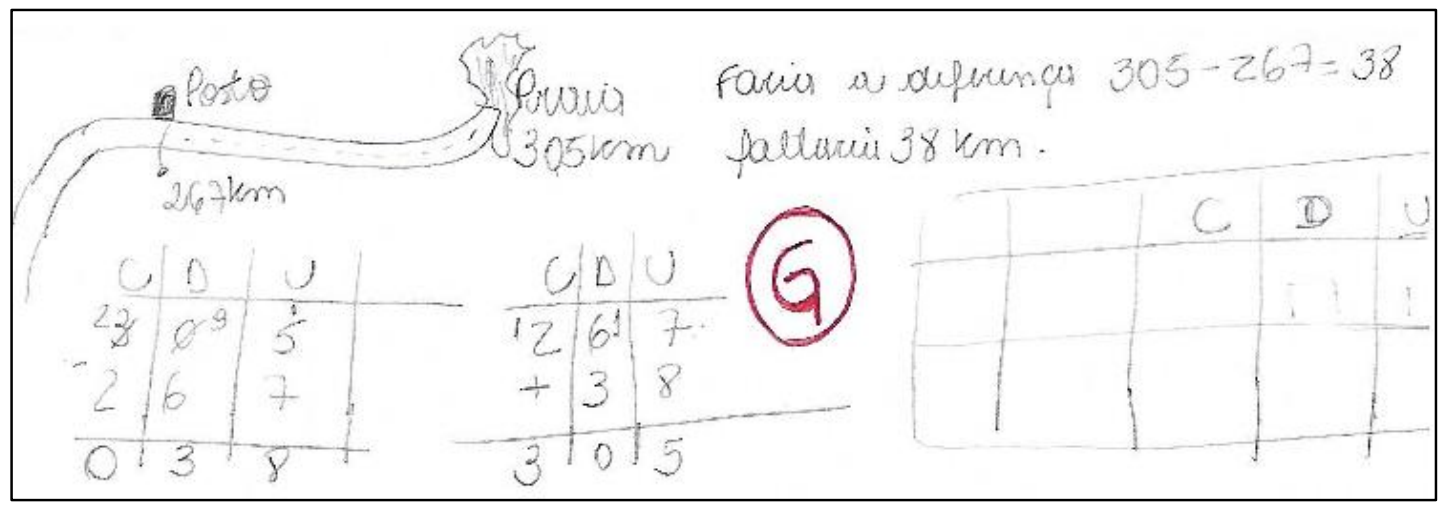

Fonte: dados da pesquisa.

Destacamos a solução apresentada por $\mathrm{G}$, pelo fato de que é indicada a estratégia do Quadro de Valor Lugar - QVL, envolvendo unidades, dezenas e centenas e a exploração de duas formas, uma aditiva e outra subtrativa, mostrando que ambas as operações podem ser pensadas juntas, sem a necessidade comum encontrada entre professores, de que a subtração vem após a adição, sendo sua operação inversa. Essas duas soluções reiteram o indicado por Bittar e Freitas (2005, p. 64), de que "Uma vez mais insistimos, o importante não é decorar regras, mas sim trabalhar com problemas variados, que levem os alunos à análise do problema e à busca de uma solução, utilizando os meios que acharem mais apropriados. "

Para completar a análise desse problema, destacamos a solução apresentada por K. O estudante indica que resolveria "pelo método do cálculo mental, de 267 para 270 faltam 3, de 270 para 300 faltam 30 e para 305 faltam mais 5, somando obtemos 38 que falta. " (estudante $\mathrm{K})$. Ele faz, ainda, o seguinte registro de seu plano:

$$
\begin{aligned}
& 267 \text { para } 270 \rightarrow 3 \\
& 270 \text { para } 300 \longrightarrow 30 \\
& \underline{300 \text { para } 305} \longrightarrow \underline{5} \\
& 38
\end{aligned}
$$


Observamos que os estudantes discutiram entre si sobre o planejamento feito e, posteriormente, sobre as soluções. Alguns deles chamavam o professor para confirmar se estavam no caminho certo. O professor deu autonomia e liberdade para tomarem decisões, buscarem soluções e, depois, discuti-las entre si, confrontando com a teoria e os exemplos debatidos previamente. Dessa forma, entendemos que os 'esquemas em ação', como citado por Nunes et al. (2009), referindo-se a Piaget, propiciaram a compreensão da adição e da subtração de números iniciais para os Anos Iniciais, como ações de juntar e retirar, respectivamente.

Na quase totalidade, os estudantes exploraram os registros semióticos e o QVL, os quais foram os assuntos mais recentes desenvolvidos em aula, fundamentando suas resoluções e respondendo ao professor. Quanto aos fatores operacionais envolvidos, indicaram a importância da decomposição de um número natural em unidades, dezenas e centenas para realizar a adição. No que diz respeito à subtração, apresentaram as ideias de retirar e completar, fundamentalmente.

\section{CONSIDERAÇÕES FINAIS}

Neste artigo, apresentamos uma investigação realizada em uma disciplina ofertada a um Programa de Pós-Graduação em Ensino de Ciências e Matemática, cujo foco são professores que atuam na Educação Infantil e nos Anos Iniciais do Ensino Fundamental, muito embora seja permitido frequentá-la, também, alunos do Mestrado Profissional e do Doutorado. A pesquisa teve como objetivo geral empregar a estratégia da Resolução de Problemas para articular conteúdos envolvendo fatos da adição e da subtração de números naturais. Para cumprir com tal objetivo, foram propostos dois problemas voltados à alfabetização matemática, com o uso superficial dos Registros de Representação Semiótica, uma vez que, em aulas anteriores, os estudantes haviam trabalhado com essa teoria.

Consideramos que a teoria dos Registros de Representação Semiótica pode ser um facilitador na alfabetização matemática, uma vez que permite ir introduzindo símbolos, nomenclaturas e conceitos, de forma até mesmo lúdica, sem, entretanto, aprofundar os fundamentos da teoria, como, por exemplo, a conversão e o tratamento. Assim, as representações simbólica e natural na resolução de problemas parecem ter propiciado um ganho na formação continuada dos participantes, mesmo para aqueles que possuem a Licenciatura em Matemática, cuja justificativa de participarem da disciplina é decorrente da inexistência de abordagem do conteúdo básico como números, adição e subtração, particularmente. 
Lorenzato (2006) aborda a questão das operações com números, na idade pré-escolar, como algo que não deve ser ensinado com qualquer algoritmo numérico escrito. Para o autor, atividades de composição, ajuntamento, justaposição, com vistas à futura adição, bem como de separação, decomposição, comparação, com vistas à adição, são primordiais para a Educação Infantil e os Anos Iniciais. Assim, é preciso iniciar com problemas simples envolvendo apenas unidades, passando àqueles envolvendo dezenas e unidades (problema 1 do presente artigo) e progredindo para as centenas, dezenas e unidades (problema 2), explorando a metodologia de Resolução de Problemas, em que o estudante interpreta o problema, destaca variáveis na busca do que deve encontrar, elabora um plano de resolução, executa esse plano, discute-o com seus pares. Finalmente, o professor organiza as soluções em conjunto com a turma. Assim, professor e alunos indicam uma provável forma didática de focar as operações de adição e de subtração no início da escolarização.

Com base no que foi proposto nesta investigação, concluímos que o objetivo delineado foi cumprido, uma vez que os participantes utilizaram os enfoques estudados sobre a Resolução de Problemas (POLYA, 2005, VAN DE WALLE, 2009, DANTE, 2003, ONUCHIC e ALEVATTO, 2011) de forma livre e espontânea como é esperado no início da escolarização e da alfabetização matemática.

Verificamos que os professores que se encontram em ação continuada puderam refletir sobre o Ensino e a Educação Matemática desejável na atual conjuntura, em que as regras não sejam dadas a priori, para que os alunos as decorem, as apliquem e interpretem os problemas, de forma que possam exercer a cidadania. Nesse sentido, habilidades como as preconizadas na BNCC para os Anos Inicias (Quadro 1), tais como ler, escrever e comparar números, estabelecer relações entre os registros numéricos e em língua materna, resolver problemas de adição e de subtração com significados de juntar, acrescentar, separar, retirar, comparar e completar quantidades; utilizar cálculo mental e estratégias diversas, além de estimar resultados, parecem ser possibilidades a serem adquiridas para o nível de escolaridade aqui detalhado por meio de atividades como as analisadas. Acreditamos e esperamos que esta investigação possa proporcionar aos leitores ideias para a prática na escola, o que, certamente, tende a contribuir para a melhoria do ensino neste nível. 


\section{REFERÊNCIAS}

BAUER, Martin W.; GASKELL, George. Pesquisa qualitativa com texto, imagem e som: um manual prático. Trad. Pedrinho Gareschi - 13. ed. Petrópolis, RJ: Vozes, 2015.

BITTAR, Marilena; FREITAS, José Luiz Magalhães de. Fundamentos e metodologias matemáticas para os ciclos iniciais do Ensino Fundamental. 2. ed. Campo Grande, MS: Ed. UFMS, 2005.

BRASIL. Secretaria de Educação Fundamental. Parâmetros curriculares nacionais: matemática/Secretaria de Educação Fundamental - Brasília: MEC/SEF, 1997, 142 p.

BRASIL. Ministério da Educação e do Desporto. Secretaria de Educação Fundamental. Referencial curricular nacional para a educação infantil / Ministério da Educação e do Desporto, Secretaria de Educação Fundamental. — Brasília: MEC/SEF, 1998. 3v.: il. Volume 1: Introdução; volume 2.

DANTE, Luiz Roberto. Didática da resolução de problemas de matemática. 12. ed. SP: Atica, 2003.

DUVAL, Reymond.. Semiósis e Pensamento Humano: registros semióticos e aprendizagens intelectuais. São Paulo: Editora Livraria da Física, 2009.

FREITAS, Aline da S. Lei de Diretrizes e Bases da Educação Nacional: estudos em virtude dos 20 anos da Lei n. 9.394/1996 / Aline da Silva Freitas, Isabel Rodrigues, Ester Zuzo. São Paulo: LTr, 2017.

GUIMARÃES, Gilda. Categorização e representação de dados: o que sabem alunos do ensino fundamental. In: Rute Borba e Gilda Guimarães (org.) A pesquisa em Educação

Matemática: repercussões na sala de aula. São Paulo: Cortez, 2009. pp. 137-176.

LOPES, Thiago Beirigo, LEIVAS, José Carlos P. Contar nos dedos: a conceitualização de número e a operação de adição. Pedagogia em Foco. Iturama (MG): v. 12, n. 7, p. 157-174, 2017.

LORENZATO, Sérgio. Educação infantil e percepção matemática. Campinas, SP: Autores Associados, 2004.

MOREIRA, Marco Antônio. Metodologias de pesquisa em ensino. São Paulo: Editora Livraria da Física, 2011.

NUNES, Terezinha.; CAMPOS, Tânia Maria Mendonça; MAGINA, Sandra; BRYANT, Peter. Educação Matemática: números e operações numéricas. 2. ed. São Paulo: Cortez, 2009.

ONUCHIC; Lourdes de la Rosa; ALLEVATO, Norma Sueli. Pesquisa em Resolução de Problemas: caminhos, avanços e novas perspectivas. Bolema, Rio Claro (SP), v. 25, n. 41, p. 73-98, dez. 2011.

POLYA, Geoge. A arte de resolver Problemas. Rio de Janeiro: Interciência, 2006. 
WALLE, John Van de. Matemática no ensino fundamental: formação de professores e aplicação em sala de aula. 6. ed. Porto Alegre: Artes Médicas, 2009.

Recebido em: 26 de outubro de 2018

Aprovado em: 27 de abril de 2019 